Check for updates

Cite this: RSC Adv., 2019, 9, 31654

Received 18th July 2019

Accepted 30th September 2019

DOI: 10.1039/c9ra05532k

rsc.li/rsc-advances

\section{Enantioselective bromination of axially chiral cyanoarenes in the presence of bifunctional organocatalysts $\uparrow$}

\author{
Yuuki Wada, Akira Matsumoto, (D) Keisuke Asano (D) * and Seijiro Matsubara (D) * \\ Enantioselective bromination of axially chiral cyanoarenes bearing high intrinsic rotational barriers via \\ dynamic kinetic resolution using bifunctional organocatalysts is reported. Sequential addition of \\ a brominating reagent in several portions at an optimized temperature was effective in accomplishing \\ high enantioselectivities.
}

Axially chiral biaryls are privileged structures in pharmaceuticals, ${ }^{1}$ asymmetric catalysts, ${ }^{2}$ functional materials, ${ }^{3}$ etc. Thus, the development of efficient methods for their synthesis is desirable to advance research in these scientific fields. Among recent accomplishments on catalytic atroposelective transformations ${ }^{4}$ toward the synthesis of densely substituted axially chiral biaryls, powerful strategies include organocatalytic dynamic kinetic resolution involving ortho-functionalization of existing biaryls via the introduction of additional rotational barriers. ${ }^{5}$ In this method, substrates should in principle have rotational barriers low enough to enable fast rotation about the biaryl axis, leading to their rapid racemization. Therefore, it is difficult to employ biaryl substrates bearing intrinsic rotational barriers, which impede their racemization. In 2015, the Miller group reported an elegant example of this type of dynamic kinetic resolution via bromination of 3-arylquinazolin-4(3H)-ones, the rotational barrier of which is $\sim 19 \mathrm{kcal} \mathrm{mol}^{-1}$, by slow addition of a brominating agent. ${ }^{5 e}$ Here, we present enantioselective bromination of axially chiral cyanoarenes bearing intrinsic rotational barriers exceeding $18 \mathrm{kcal} \mathrm{mol}^{-1}$ (Scheme 1). To the best of our knowledge, there has been no report of a catalytic asymmetric reaction affording axially chiral cyanoarenes, ${ }^{6}$ despite their prevalence in bioactive agents ${ }^{7}$ and the rich chemistry of cyano compounds as synthetic intermediates. ${ }^{8}$

Table 1 shows the optimization of reaction conditions. We started our investigation using 1-(3-hydroxyphenyl)-2-

Department of Material Chemistry, Graduate School of Engineering, Kyoto University, Kyotodaigaku-Katsura, Nishikyo, Kyoto 615-8510, Japan. E-mail: asano.keisuke.5w@ kyoto-u.ac.jp; matsubara.seijiro.2e@kyoto-u.ac.jp; Fax: +8175383 2438; Tel: +81 75 $3837571 ;+81753837130$

$\dagger$ Electronic supplementary information (ESI) available: Experimental procedures, analytical and spectroscopic data for synthetic compounds, and copies of NMR. CCDC 1936455. For ESI and crystallographic data in CIF or other electronic format see DOI: 10.1039/c9ra05532k

‡. Present address: Graduate School of Pharmaceutical Sciences, Kyoto University, Yoshida-Shimoadachi, Sakyo, Kyoto 606-8501, Japan. naphthonitrile (1a) and $N$-bromoacetamide (NBA, 4a) as the brominating reagent with $10 \mathrm{~mol} \%$ quinine-derived bifunctional catalysts $3 \mathbf{a}-3 \mathbf{c}$ in $\mathrm{CH}_{2} \mathrm{Cl}_{2}$ at $25{ }^{\circ} \mathrm{C}$. Urea and amide catalysts $3 \mathbf{a}$ and $3 \mathbf{c}$, respectively, afforded $2 \mathbf{a}$ in higher enantioselectivities than the thiourea catalyst $\mathbf{3 b}$ (Table 1, entries 13). ${ }^{9}$ Other catalysts $\mathbf{3 d}$ and $\mathbf{3 e}$, bearing a cyclohexanediamine framework, and 3f, bearing a binaphthyl framework, resulted in poor enantioselectivities (Table 1, entries $4-6$ ).$^{10}$ Using $\mathbf{3 a}$ and $3 \mathbf{c}$, lower reaction temperatures were investigated (Table 1, entries 7-10); 3c gave higher enantioselectivity at $-40{ }^{\circ} \mathrm{C}$, although the reactions did not proceed at all at $-60{ }^{\circ} \mathrm{C}$. By screening different solvents, $\mathrm{CH}_{2} \mathrm{Cl}_{2}$ was identified as the most suitable solvent from the viewpoints of both yield and enantioselectivity (Table 1, entries 9 and 11-16). Other brominating reagents (Fig. 1) were also investigated; NBA (4a) still afforded the best enantioselectivities (Table 1, entries 9 and 17-19). The decrease in the loading of $3 \mathbf{c}$ to $5 \mathrm{~mol} \%$ slightly improved the enantioselectivity, although a longer reaction time $(48 \mathrm{~h})$ was necessary (Table 1 , entry 20). Next, using the thus-optimized conditions, reactions with shorter reaction times $(24 \mathrm{~h}, 12 \mathrm{~h}$, and $6 \mathrm{~h}$ ) were carried out (Table 1, entries 21-23); the enantioselectivity was improved while the conversions decreased with decreasing reaction time. These results imply that the racemization of 1a at $-40{ }^{\circ} \mathrm{C}$ is not rapid enough to make use of dynamic kinetic resolution.

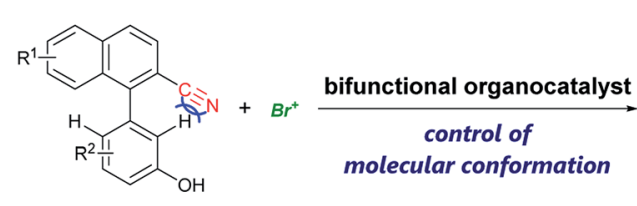

intrinsic rotational barrier

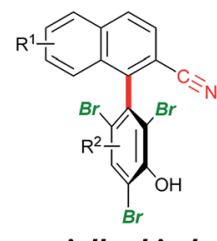

axially chiral cyanoarenes
Scheme 1 Enantioselective bromination of axially chiral cyanoarenes using bifunctional organocatalysts. 


(a)
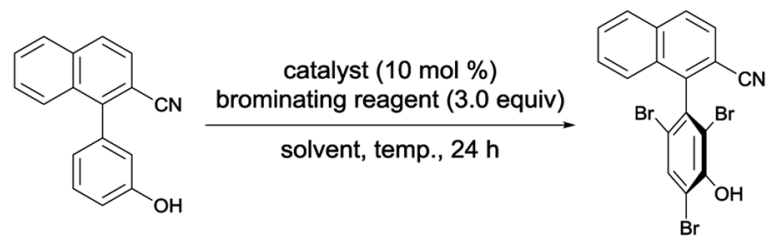

$1 a$

2a

\begin{tabular}{|c|c|c|c|c|c|c|}
\hline Entry & Catalyst & Brominating reagent & Solvent & Temp. $\left({ }^{\circ} \mathrm{C}\right)$ & Yield $^{b}(\%)$ & ee $(\%)$ \\
\hline 1 & $3 \mathbf{a}$ & NBA (4a) & $\mathrm{CH}_{2} \mathrm{Cl}_{2}$ & 25 & 81 & 26 \\
\hline 2 & $3 \mathbf{b}$ & NBA (4a) & $\mathrm{CH}_{2} \mathrm{Cl}_{2}$ & 25 & 87 & 6 \\
\hline 3 & $3 c$ & NBA (4a) & $\mathrm{CH}_{2} \mathrm{Cl}_{2}$ & 25 & 89 & 18 \\
\hline 4 & $3 d$ & NBA $(4 a)$ & $\mathrm{CH}_{2} \mathrm{Cl}_{2}$ & 25 & 83 & 6 \\
\hline 5 & $3 \mathbf{e}$ & NBA (4a) & $\mathrm{CH}_{2} \mathrm{Cl}_{2}$ & 25 & 85 & 3 \\
\hline 6 & $3 f$ & NBA (4a) & $\mathrm{CH}_{2} \mathrm{Cl}_{2}$ & 25 & 79 & 3 \\
\hline 7 & $3 a$ & NBA (4a) & $\mathrm{CH}_{2} \mathrm{Cl}_{2}$ & -40 & 82 & 20 \\
\hline 8 & $3 a$ & NBA (4a) & $\mathrm{CH}_{2} \mathrm{Cl}_{2}$ & -60 & $<1$ & - \\
\hline 9 & $3 c$ & NBA (4a) & $\mathrm{CH}_{2} \mathrm{Cl}_{2}$ & -40 & 83 & 41 \\
\hline 10 & $3 c$ & NBA (4a) & $\mathrm{CH}_{2} \mathrm{Cl}_{2}$ & -60 & $<1$ & - \\
\hline 11 & $3 c$ & NBA (4a) & $\mathrm{CHCl}_{3}$ & -40 & 21 & 54 \\
\hline 12 & $3 c$ & NBA (4a) & Toluene & -40 & 18 & -10 \\
\hline 13 & $3 c$ & NBA (4a) & THF & -40 & 13 & -2 \\
\hline 14 & $3 c$ & NBA (4a) & $\mathrm{Et}_{2} \mathrm{O}$ & -40 & 46 & -20 \\
\hline 15 & $3 c$ & NBA (4a) & EtOAc & -40 & 68 & -4 \\
\hline 16 & $3 c$ & NBA (4a) & EtOH & -40 & $<5$ & - \\
\hline 17 & $3 c$ & $\mathrm{DBH}(\mathbf{4} \mathbf{b})$ & $\mathrm{CH}_{2} \mathrm{Cl}_{2}$ & -40 & 79 & 1 \\
\hline 18 & $3 c$ & NBS (4c) & $\mathrm{CH}_{2} \mathrm{Cl}_{2}$ & -40 & 82 & 20 \\
\hline 19 & $3 c$ & NBP (4d) & $\mathrm{CH}_{2} \mathrm{Cl}_{2}$ & -40 & 79 & -5 \\
\hline $20^{c, d}$ & $3 c$ & NBA (4a) & $\mathrm{CH}_{2} \mathrm{Cl}_{2}$ & -40 & 85 & 49 \\
\hline $21^{c, e}$ & $3 c$ & NBA (4a) & $\mathrm{CH}_{2} \mathrm{Cl}_{2}$ & -40 & 51 & 59 \\
\hline $22^{c_{2} f}$ & $3 c$ & NBA (4a) & $\mathrm{CH}_{2} \mathrm{Cl}_{2}$ & -40 & 33 & 66 \\
\hline $23^{c, g}$ & $3 c$ & NBA (4a) & $\mathrm{CH}_{2} \mathrm{Cl}_{2}$ & -40 & 17 & 71 \\
\hline
\end{tabular}
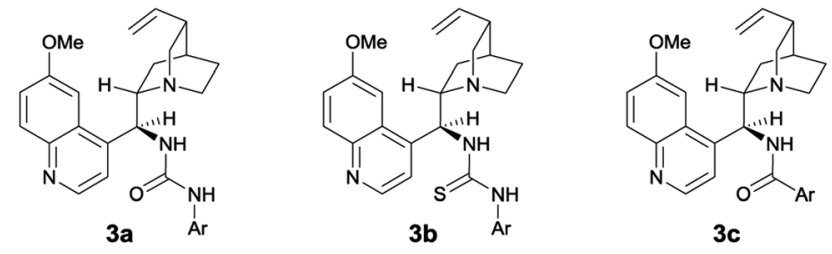

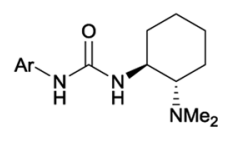

3d

$\mathrm{Ar}=3,5-\left(\mathrm{CF}_{3}\right)_{2} \mathrm{C}_{6} \mathrm{H}_{3}$<smiles>CN(C)[C@@H]1CCCC[C@H]1Nc1c(N)c(=O)c1=O</smiles>

$3 e$<smiles>CNC(=O)Nc1ccc2ccccc2c1-c1c(N(C)C)ccc2ccccc12</smiles>

3f

${ }^{a}$ Reactions were run using $1 \mathrm{a}(0.10 \mathrm{mmol})$, the brominating reagent $(0.30 \mathrm{mmol})$, and the catalyst $(0.010 \mathrm{mmol})$ in the solvent $(10 \mathrm{~mL}) .{ }^{b}$ Isolated yields. ${ }^{c}$ Reactions were run using $3 \mathbf{c}(0.0050 \mathrm{mmol}){ }^{d}$ Reaction was run for $48 \mathrm{~h} .{ }^{e}$ Reaction was run for 24 h. ${ }^{f}$ Reaction was run for $12 \mathrm{~h} .{ }^{g}$ Reaction was run for $6 \mathrm{~h}$.

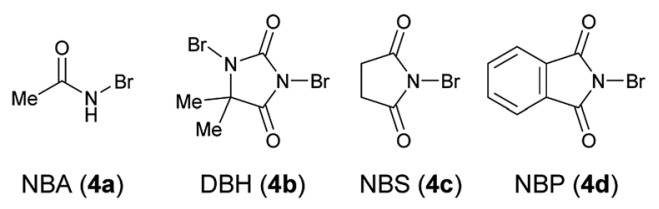

Fig. 1 Brominating reagents.
Subsequently, to improve the efficiency of dynamic kinetic resolution by retarding the enantiodetermining bromination, ${ }^{5 e}$ 4a was added sequentially in five portions (Fig. 2). ${ }^{11}$ Although the procedure hardly affected the results at $-40{ }^{\circ} \mathrm{C}$, the enantioselectivity was greatly improved for reactions carried out at $-20{ }^{\circ} \mathrm{C}$ and $-30{ }^{\circ} \mathrm{C}$. Such effects were smaller at temperatures above $-10{ }^{\circ} \mathrm{C}$. 


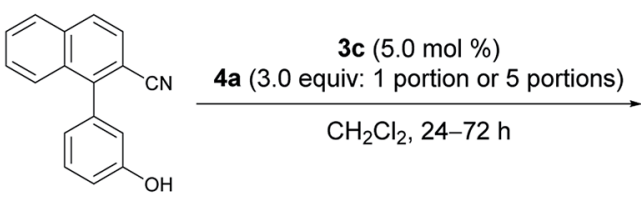

$1 \mathbf{a}$

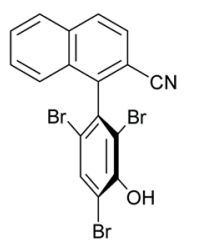

$2 \mathbf{a}$

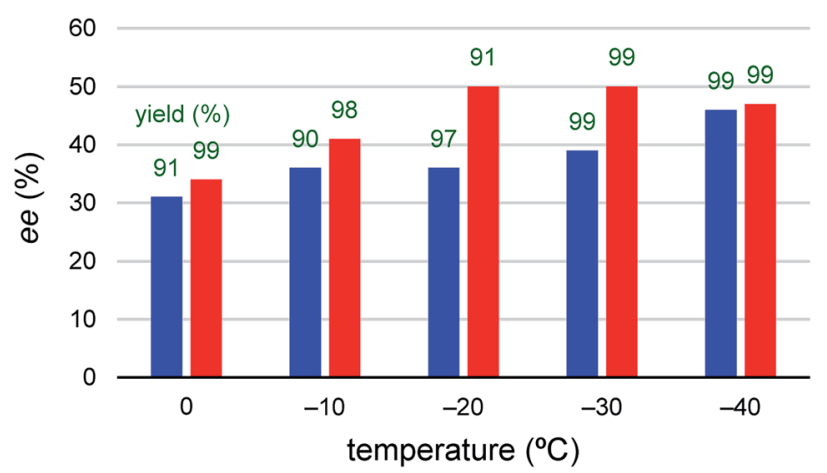

Fig. 2 Investigations of temperatures and procedures. Blue bar: reactions were run with $4 \mathrm{a}$ added in 1 portion. Red bar: reactions were run with $4 \mathrm{a}$ added in 5 portions. Green values represent yields of $2 a$ isolated after silica gel column chromatography. At $0,-10,-20$, and $-30^{\circ} \mathrm{C}$, reactions were run for $24 \mathrm{~h}$; at $-40^{\circ} \mathrm{C}$, reactions were run for $72 \mathrm{~h}$.

Next, at $-30{ }^{\circ} \mathrm{C}$ and $-40{ }^{\circ} \mathrm{C}$, respectively, the relationships between enantioselectivity and yield were investigated (Fig. 3). Reactions were carried out using various amounts of 4a. At both temperatures, the enantioselectivity decreased as the yield increased; however, the quantitative reactions also

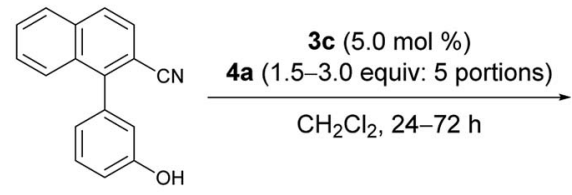

$1 \mathbf{a}$

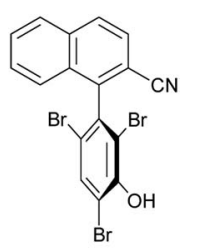

$2 a$

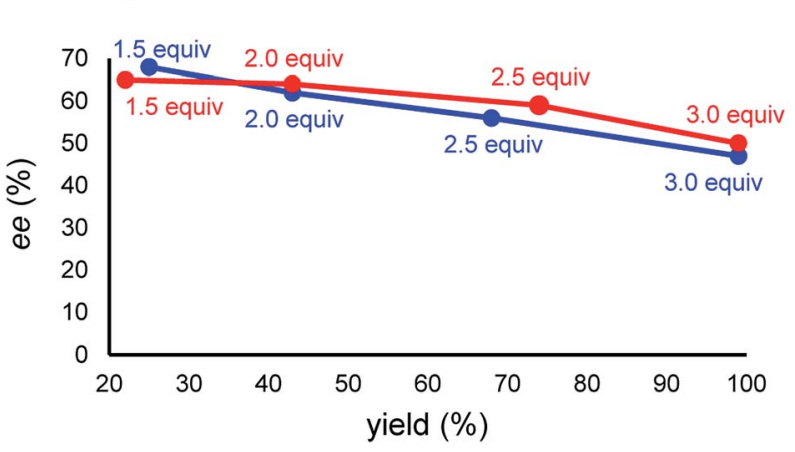

Fig. 3 Relationships between ee and yield. Red line: reactions were run at $-30{ }^{\circ} \mathrm{C}$ for $24 \mathrm{~h}$ with $4 \mathrm{a}$ added in 5 portions. Blue line: reactions were run at $-40{ }^{\circ} \mathrm{C}$ for $72 \mathrm{~h}$ with $4 \mathrm{a}$ added in 5 portions. Red and blue values represent amounts of $4 \mathrm{a}$ used for each reaction. exhibited some enantioselectivity $\left(-30{ }^{\circ} \mathrm{C}\right.$ : $99 \%$ yield, $50 \%$ ee; $-40{ }^{\circ} \mathrm{C}: 99 \%$ yield, $47 \%$ ee), implying the presence of the characteristics of dynamic kinetic resolution. In addition, although the enantioselectivity was better at $-40{ }^{\circ} \mathrm{C}$ than $-30{ }^{\circ} \mathrm{C}$ when the yield was low, the relationship became reversed as the yield increased; hence, the efficiency of dynamic kinetic resolution was revealed to be better at $-30{ }^{\circ} \mathrm{C}$ than at $-40{ }^{\circ} \mathrm{C}$. Furthermore, when 1.5 equiv. of $4 \mathrm{a}$ were used at $-30{ }^{\circ} \mathrm{C}$ affording $2 \mathrm{a}$ in $22 \%$ yield with $65 \%$ ee, the ortho-monobrominated product 1a-Br (Fig. 4) was also obtained with $75 \%$ ee (see Scheme S1 in the ESI $\uparrow$ for details). It shows that the bromination at one of the ortho-positions introduces a rotational barrier high enough to set the chiral axis, which is consistent with the rotational barriers calculated at the M06-2X/6-311++G(2d,3p)//B3LYP/6-31+G(d,p) level of theory (Fig. 4).

Under the conditions of using $3 \mathbf{c}$ as the catalyst at $-30{ }^{\circ} \mathrm{C}$ with 3 equiv. of $\mathbf{4 a}$ added sequentially in five portions, other substrates bearing substituted phenols were also investigated (Scheme 2). ${ }^{\mathbf{1 2}}$ First, substrates $\mathbf{1 b - 1 e}$ bearing a substituent at the meta-position were investigated. While the electron-deficient substrate $\mathbf{1 b}$ resulted in poor enantioselectivity, 1c and 1d bearing aliphatic substituents gave improved enantioselectivities; however, substrate 1e with a methoxy group resulted in low enantioselectivity. In addition, substrates $\mathbf{1 f - 1 i}$ bearing substituents at the para-positions of the biaryl axis were then examined; phenol $\mathbf{2 h}$ bearing a methyl group resulted in higher enantioselectivities than phenols $2 \mathbf{f}$ and $\mathbf{2 g}$ bearing electron-withdrawing groups and $2 \mathbf{i}$ bearing a methoxy group. These results suggest that aliphatic substituents might efficiently facilitate the racemization of $\mathbf{1}$ during bromination, leading to dynamic kinetic resolution with greater enantioselectivity. Utilizing this methodology with the characteristics of dynamic kinetic resolution, the reactions of $\mathbf{1 c}$ and $\mathbf{1 g}$ were also carried out using a sub-stoichiometric amount of $\mathbf{4 a}$ (Scheme 3); higher enantioselectivities were accomplished albeit with lower yields. ${ }^{13}$ The absolute configuration of $2 \mathbf{c}$ was determined by X-ray crystallography (see the ESI $\uparrow$ for details), and the configurations of all other products were assigned analogously.

In summary, we present enantioselective bromination of axially chiral cyanoarenes bearing high intrinsic rotational barriers via dynamic kinetic resolution using bifunctional<smiles>N#Cc1ccc2ccccc2c1-c1cccc(O)c1</smiles><smiles>N#Cc1ccc2ccccc2c1-c1cccc(O)c1Br</smiles><smiles>[111In]</smiles>
$18.4 \mathrm{kcal} / \mathrm{mol}$

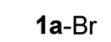
$38.9 \mathrm{kcal} / \mathrm{mol}$<smiles>N#Cc1ccc2ccccc2c1-c1c(Br)cc(Br)c(O)c1Br</smiles>

2a

$51.7 \mathrm{kcal} / \mathrm{mol}$
Fig. 4 Rotational barriers of substrate, intermediate, and product calculated at the M06-2X/6-311++G(2d,3p)//B3LYP/6-31+G(d,p) level of theory. 
<smiles>N#Cc1ccc2ccccc2c1-c1cc(O)cc(Br)c1</smiles>

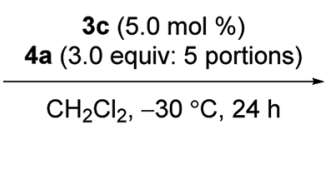

1
$2 a$
$99 \%$ $51 \%$ ee

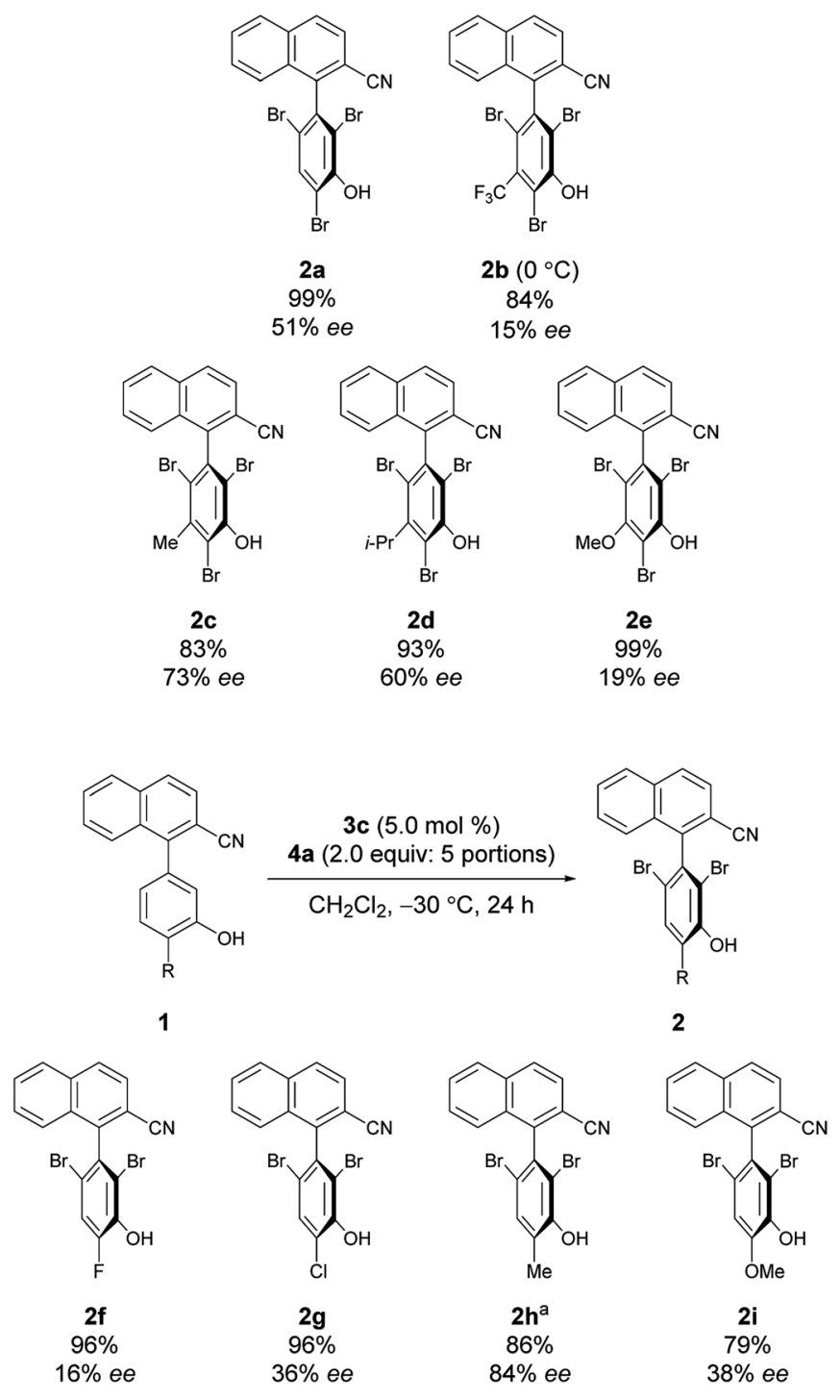

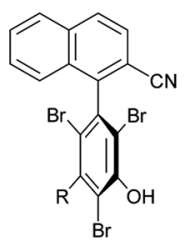

2
Scheme 2 Reactions of substrates with substituted phenols. ${ }^{a}$ Reaction was run for $72 \mathrm{~h}$.

organocatalysts. The sequential addition of $4 \mathbf{a}$ in several portions at the optimized temperature was effective in improving the enantioselectivity. Although the enantioselectivities are still moderate using the current catalytic system, the guidelines for designing catalytic asymmetric syntheses of axially chiral cyanoarenes were established. Further studies on the additional optimization and application of this methodology to the construction of densely substituted axially chiral biaryls are currently underway.
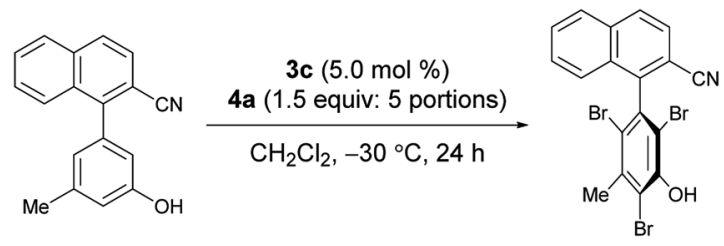

$1 c$

2c

$26 \%$

$88 \%$ ee
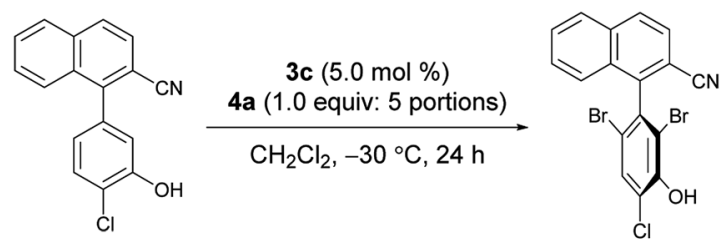

19

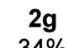

$34 \%$
$51 \%$ ee

Scheme 3 Reactions with a substoichiometric amount of $4 a$

\section{Conflicts of interest}

There are no conflicts to declare.

\section{Acknowledgements}

This work was supported financially by the Japanese Ministry of Education, Culture, Sports, Science and Technology (JP15H05845, JP16K13994, JP17K19120, JP18K14214, and JP18H04258). K. A. also acknowledges the Naito Foundation, Research Institute for Production Development, the Tokyo Biochemical Research Foundation, the Uehara Memorial Foundation, the Kyoto University Foundation, the Institute for Synthetic Organic Chemistry, Toyo Gosei Memorial Foundation, the Sumitomo Foundation, and Fukuoka Naohiko Memorial Foundation. A. M. also acknowledges the Japan Society for the Promotion of Science for Young Scientists for the fellowship support.

\section{Notes and references}

1 (a) G. Bringmann and D. Menche, Acc. Chem. Res., 2001, 34, 615; (b) M. C. Kozlowski, B. J. Morgan and E. C. Linton, Chem. Soc. Rev., 2009, 38, 3193; (c) G. Bringmann, T. Gulder, T. A. M. Gulder and M. Breuning, Chem. Rev., 2011, 111, 563; (d) A. Zask, J. Murphy and G. A. Ellestad, Chirality, 2013, 25, 265; (e) J. E. Smyth, N. M. Butler and P. A. Keller, Nat. Prod. Rep., 2015, 32, 1562; (f) C. L. Covington, F. M. S. Junior, J. H. S. Silva, R. M. Kuster, M. B. de Amorim and P. L. Polavarapu, J. Nat. Prod., 2016, 79, 2530.

2 (a) M. McCarthy and P. J. Guiry, Tetrahedron, 2001, 57, 3809; (b) Y. Chen, S. Yekta and A. K. Yudin, Chem. Rev., 2003, 103, 3155; (c) J. M. Brunel, Chem. Rev., 2005, 105, 857; (d) T. P. Yoon and E. N. Jacobsen, Science, 2003, 299, 1691. 
3 (a) Q. Li, L. Green, N. Venkataraman, I. Shiyanovskaya, A. Khan, A. Urbas and J. W. Doane, J. Am. Chem. Soc., 2007, 129, 12908; (b) H. Hayasaka, T. Miyashita, M. Nakayama, K. Kuwada and K. Akagi, J. Am. Chem. Soc., 2012, 134, 3758; (c) Y.-L. Wu, F. Ferroni, S. Pieraccini, W. B. Schweizer, B. B. Frank, G. P. Spada and F. Diederich, Org. Biomol. Chem., 2012, 10, 8016; (d) L. Pu, Acc. Chem. Res., 2012, 45, 150; (e) G. Wei, S. Zhang, C. Dai, Y. Quan, Y. Cheng and C. Zhu, Chem.-Eur. J., 2013, 19, 16066.

4 For selected recent reviews on enantioselective syntheses of axially chiral compounds, see ref. 1 and the following:(a) P. G. Cozzi, E. Emer and A. Gualandi, Angew. Chem., Int. Ed., 2011, 50, 3847; (b) O. Quinonero, C. Bressy and X. Bugaut, Angew. Chem., Int. Ed., 2014, 53, 10861; (c) J. Wencel-Delord, A. Panossian, F. R. Leroux and F. Colobert, Chem. Soc. Rev., 2015, 44, 3418; (d) G. Ma and M. P. Sibi, Chem.-Eur. J., 2015, 21, 11644; (e) G. Bencivenni, Synlett, 2015, 26, 1915; $(f)$ E. Kumarasamy, R. Raghunathan, M. P. Sibi and J. Sivaguru, Chem. Rev., 2015, 115, 11239; $(g)$ S. Shirakawa, S. Liu and S. Kaneko, Chem.-Asian J., 2016, 11, 330; (h) P. Renzi, Org. Biomol. Chem., 2017, 15, 4506; (i) B. Zilate, A. Castrogiovanni and C. Sparr, ACS Catal., 2018, 8, 2981; (j) O. Baudoin, Eur. J. Org. Chem., 2005, 4223; (k) G. Bringmann, A. J. P. Mortimer, P. A. Keller, M. J. Gresser, J. Garner and M. Breuning, Angew. Chem., Int. Ed., 2005, 44, 5384; (l) D. Zhang and Q. Wang, Coord. Chem. Rev., 2015, 286, 1; $(m)$ A. H. Cherney, N. T. Kadunce and S. E. Reisman, Chem. Rev., 2015, 115, 9587; (n) P. Loxq, E. Manoury, R. Poli, E. Deydier and A. Labande, Coord. Chem. Rev., 2016, 308, 131; (o) K. Tanaka, Chem.-Asian J., 2009, 4, 508.

5 (a) J. L. Gustafson, D. Lim and S. J. Miller, Science, 2010, 328, 1251; (b) T. P. Pathak and S. J. Miller, J. Am. Chem. Soc., 2012, 134, 6120; (c) K. T. Barrett and S. J. Miller, J. Am. Chem. Soc., 2013, 135, 2963; (d) K. T. Barrett, A. J. Metrano, P. R. Rablen and S. J. Miller, Nature, 2014, 509, 71; (e) M. E. Diener, A. J. Metrano, S. Kusano and S. J. Miller, J. Am. Chem. Soc., 2015, 137, 12369; $(f)$ R. Miyaji, K. Asano and S. Matsubara, J. Am. Chem. Soc., 2015, 137, 6766; (g) R. Miyaji, K. Asano and S. Matsubara, Chem.-Eur. J., 2017, 23, 9996; (h)
R. Miyaji, Y. Wada, A. Matsumoto, K. Asano and S. Matsubara, Beilstein J. Org. Chem., 2017, 13, 1518.

6 For the synthesis of axially chiral cyanoarenes using optically active starting materials, see: J. Liu, H.-X. Zheng, C.-Z. Yao, B.-F. Sun and Y.-B. Kang, J. Am. Chem. Soc., 2016, 138, 3294. 7 (a) J. Clayden, W. J. Moran, P. J. Edwards and S. R. LaPlante, Angew. Chem., Int. Ed., 2009, 48, 6398; (b) S. R. LaPlante, L. D. Fader, K. R. Fandrick, D. R. Fandrick, O. Hucke, R. Kemper, S. P. F. Miller and P. J. Edwards, J. Med. Chem., 2011, 54, 7005.

8 (a) K. Friedrich and K. Wallenfels, in The Chemistry of the Cyano Group, ed. Z. Rappaport, John Wiley \& Sons, 1970, ch. 2; (b) A. J. Fatiadi, in The Chemistry of Triple-Bonded Functional Groups, ed. S. Patai and Z. Rappaport, John Wiley \& Sons, 1983, ch. 26, vol. 2.

9 The replacement of the cyano group with an ethynyl group in 1a gave much lower enantioselectivity in the presence of 3c; the replacement of the $\mathrm{NH}$ group with an NMe group in $\mathbf{3 c}$ gave much lower enantioselectivity and catalytic activity in the reaction of 1a; the replacement of the $\mathrm{OH}$ group with an OMe group in 1a resulted in no reaction in the presence of 3c. These results suggest that the cyano and $\mathrm{OH}$ groups of $\mathbf{1 a}$ and the $\mathrm{NH}$ group of $\mathbf{3 c}$ are involved in hydrogen bonding between 1a and 3c during catalysis. See Scheme $\mathrm{S} 2$ in the $\mathrm{ESI} \dagger$ for details.

10 Results of further catalyst screening are described in the ESI (Table $\mathrm{S} 1 \dagger$ ).

11 Slow addition of 4 a over hours resulted in low yields, probably because $\mathbf{4 a}$ was decomposed in its $\mathrm{CH}_{2} \mathrm{Cl}_{2}$ solution in the syringe while addition after being left for a while.

12 It was difficult to prepare substrates bearing substituted 2naphthonitriles.

13 The reaction of $\mathbf{1 h}$ using 0.5 equiv. of $\mathbf{4 a}$ afforded an orthomonobrominated product in $43 \%$ yield with $81 \%$ ee (see Scheme S3 in the ESI $\dagger$ for details), which is not higher than the result ( $84 \%$ ee) obtained in Scheme 2 . These results also imply that aliphatic substituents increase the efficiency of dynamic kinetic resolution. 